Gretchen Shelesky, MD, MS; Gregory Castelli, PharmD, BCPS, BC-ADM UPMC St. Margaret, Pittsburgh, PA

DEPUTY EDITOR Shailendra Prasad, MBBS, MPH

University of Minnesota North Memorial Family Medicine Residency Program, Minneapolis, MN

doi: $10.12788 /$ jfp. 0154

\title{
An alternative regimen to reduce risk of asthma exacerbations
}

\author{
This study supports the use of an ICS/LABA as needed \\ for adults with intermittent, mild persistent, and \\ moderate persistent asthma.
}

\section{PRACTICE CHANGER}

Use an inhaled corticosteroid plus longacting beta-agonist (ICS/LABA) prn for intermittent, mild persistent, or moderate persistent asthma for fewer moderate and severe exacerbations and the same daily symptom control as scheduled ICS with a short-acting beta-agonist (SABA) prn. ${ }^{1}$

STRENGTH OF RECOMMENDATION

A: Based on a single, good-quality, multicenter, randomized controlled trial. ${ }^{1}$

Hardy J, Baggott C, Fingleton J, et al; PRACTICAL study team. Budesonide-formoterol reliever therapy versus maintenance budesonide plus terbutaline reliever therapy in adults with mild to moderate asthma (PRACTICAL): a 52-week, open-label, multicentre, superiority, randomised controlled trial. Lancet. 2019;394:919-928. Published correction appears in Lancet. 2020;395:1422. ${ }^{1}$

\section{ILLUSTRATIVE CASE}

A 37-year-old woman with moderate persistent asthma, controlled on the ICS fluticasone (110 $\mathrm{\mu g}$ twice a day) presents to you for an annual exam. She uses her rescue albuterol inhaler a few times per month. Her last exacerbation was 2 years ago. She has never smoked. She is concerned about continuing to take an ICS every day. What alternative regimen would you recommend for this patient?

A ccording to the Centers for Disease Control and Prevention, asthma affected 24.7 million children and adults in the United States in 2018, accounting for 9.8 million physician visits and $1.6 \mathrm{mil}-$ lion emergency department (ED) visits. ${ }^{2}$ The
National Institutes of Health (NIH) asthma care guidelines, updated in 2020 , recommend a SABA prn as step 1 for intermittent asthma, along with nonpharmacologic management. ${ }^{3}$ Once a patient has persistent asthma, treatment escalation to step 2 calls for use of daily maintenance inhalers as the preferred treatment option. ${ }^{3}$

However, the 2020 Global Initiative for Asthma (GINA) warns that an as-needed SABA does not protect patients from severe exacerbations, and regular use of a SABA alone ( $>3$ inhalers/year) can increase the risk of exacerbations. ${ }^{4} \mathrm{~A}$ meta-analysis and systematic review from 2018 showed that using an ICS/LABA-scheduled and prn for rescue-had lower risk of asthma exacerbations compared with scheduled ICS/LABA with SABA prn for rescue in patients with moderate-to-severe persistent asthma. ${ }^{5}$ Interestingly, the updated $2020 \mathrm{NIH}$ guidelines have adopted this strategy. SABA use prn is no longer recommended for rescue in mild and moderate persistent asthma, and the guidelines now suggest that ICS/LABA be used as rescue in addition to daily medication. ${ }^{3}$

Although evidence has been mounting for adding the as-needed ICS/LABA for rescue in patients on daily medication, the mainstay has been to provide a SABA prn for rescue use. ${ }^{5}$ Confusing matters more, evidence is emerging that as-needed ICS/LABA for rescue alone in certain patients is safe and effective. The randomized controlled Novel START study, an open-label, parallel-group 
study, compared ICS/LABA prn vs scheduled ICS with SABA prn vs SABA alone prn in adult patients with intermittent or mild persistent asthma. ${ }^{6}$ ICS/LABA prn prevented more exacerbations and provided better daily control than as-needed SABA alone. ${ }^{6}$ In addition, ICS/LABA as needed resulted in fewer severe exacerbations but potentially poorer daily control than ICS with SABA as needed. ${ }^{6}$

The PRACTICAL study investigated treatment of patients with intermittent, mild persistent, and moderate persistent asthma. ${ }^{1}$

\section{STUDY SUMMARY}

\section{ICS/LABA prn reduced risk of severe exacerbations}

The randomized controlled PRACTICAL study was a 52-week, open-label, parallelgroup, superiority trial in New Zealand that compared as-needed ICS/LABA $(n=437)$ to scheduled ICS plus as-needed SABA ( $\mathrm{n}=448)$. Patients were 18 to 75 years old, with a diagnosis of asthma. Applying $\mathrm{NIH}$ guideline definitions, these patients would fall into intermittent, mild persistent, or moderate persistent asthma categories, and were on either as-needed SABA alone or a scheduled low- to moderate-dose ICS plus an asneeded SABA in the previous 12 weeks.

Patients on an as-needed SABA prerandomization had to have at least 1 of the following: (1) asthma symptoms or need for a SABA at least twice in the past 4 weeks; (2) at least 1 nighttime awakening due to asthma in the past 4 weeks; or (3) a severe exacerbation requiring oral corticosteroids in the past year. Patients on scheduled ICS plus SABA prn prerandomization were required to have either: (1) low or moderate ICS dosing with partly or well-controlled asthma; or (2) if uncontrolled, poor inhaler technique or adherence.

Patients in the ICS/LABA group were given budesonide $200 \mu \mathrm{g} /$ formoterol $6 \mu \mathrm{g}$, 1 puff prn, and patients in the ICS plus as-needed SABA group were given budesonide $200 \mu \mathrm{g}$, 1 puff twice daily, and terbutaline $250 \mu \mathrm{g}$, 2 puffs prn. All patients received an asthma action plan that provided guidance on when to seek medical care if asthma worsened, as well as a log to note urgent medical visits and use of systemic corticosteroids. A subset of patients had adherence and dosing monitored by electronic inhaler usage monitors. Patients were seen at $0,4,16,28,40$, and 52 weeks.

I Outcomes. The primary outcome was the number of severe exacerbations per patient per year, defined as treatment with oral corticosteroids for $\geq 3$ days or ED visit or hospital admission requiring systemic corticosteroids. Among the secondary outcomes were number of moderate and severe exacerbations per patient per year (defined as an unplanned medical visit: primary care, ED, hospital admission, and any duration of steroids); time to first severe exacerbation; assessment with the Asthma Control Questionnaire (ACQ-5); adverse outcomes; and quantity of ICS used (analysis done only for the subset with electronic inhaler monitoring).

ACQ- 5 takes the mean of 5 questions assessing asthma control in the previous week, with each question ranging from 0 (no impairment) to 6 (maximum impairment). The statistician was blinded to the primary outcome.

I Results. The rate of severe exacerbations per patient per year was 0.119 in the as-needed ICS/LABA group vs 0.172 in the scheduled ICS plus as-needed SABA group (relative rate $[\mathrm{RR}]=0.69 ; 95 \%$ confidence interval [CI], 0.48-1.00). Time to first severe asthma exacerbation was longer in the asneeded ICS/LABA group (hazard ratio $=0.60$; 95\% CI, 0.40-0.91). The rate of moderate and severe exacerbations per patient per year was lower in the as-needed ICS/LABA group: 0.165 vs 0.237 ( $\mathrm{RR}=0.70 ; 95 \% \mathrm{CI}, 0.51-0.95)$.

ACQ-5 scores were similar at all time points (mean difference $=0.07 ; 95 \% \mathrm{CI}$, -0.03 to 0.17 ). Adverse events were similar between groups (most commonly nasopharyngitis in both groups). Less ICS was used in the ICS/LABA group (difference $=-126.5 \mu \mathrm{g}$ per day; $95 \% \mathrm{CI},-171.0$ to -81.9 ).

\section{WHAT'S NEW}

\section{Study lends support to recent recommendations}

This study represents a compelling, realworld look at emerging asthma recommendations. This was the first comprehensive

\section{$>$}

This study represents a compelling, real-world look at emerging asthma recommendations. 
study to show that as-needed ICS/LABA therapy prevents more moderate and severe exacerbations and lengthens the time to first severe exacerbation, compared with scheduled ICS plus SABA prn in intermittent, mild persistent, or moderate persistent asthma. These data have been incorporated into the GINA guidelines, which recommend ICS/ LABA prn for step 2.

\section{CAVEATS}

\section{Potential bias in study design}

The LABA used in this study was formoterol, which has a quicker onset than other LABAs. It is likely that not all LABAs can be used the same way, and both the NIH and GINA guidelines call it out specifically. Additionally, the study's open-label design can introduce bias but may be the only way to simulate the real-world actions of our patients. Prior studies used placebo inhalers to keep participants and providers blinded but then could not capitalize on the behavior of using only an inhaler prn (as with the ICS/LABA of this study). Finally, there is discordance between the NIH and GINA asthma guidelines on how to use these data.

\section{CHALLENGES TO IMPLEMENTATION}

\section{Cost of ICS/LABA may limit its use}

Cost is the largest barrier to implementation. Budesonide costs 6 to 10 times more than alb- uterol per inhaler (retail price of $\$ 281-\$ 427$ vs \$17-\$92, respectively). ${ }^{7,8}$ However, cost differences are likely negated for patients already on a maintenance inhaler.

JFP

\section{ACKNOWLEDGEMENT}

The PURLs Surveillance System was supported in part by Grant Number UL1RR024999 from the National Center For Research Resources, a Clinical Translational Science Award to the University of Chicago. The content is solely the responsibility of the authors and does not necessarily represent the official views of the National Center For Research Resources or the National Institutes of Health.

Copyright (c) 2021. The Family Physicians Inquiries Network. All rights reserved.

\section{References}

1. Hardy J, Baggott C, Fingleton J, et al; PRACTICAL study team. Budesonide-formoterol reliever therapy versus maintenance budesonide plus terbutaline reliever therapy in adults with mild to moderate asthma (PRACTICAL): a 52-week, open-label, multicentre, superiority, randomised controlled trial. Lancet 2019;394:919-928. Published correction appears in Lancet. 2020;395:1422.

2. Centers for Disease Control and Prevention. Summary Health Statistics: National Health Interview Survey, 2018. Accessed February 17,2021 . https://ftp.cdc.gov/pub/Health_Statistics/NCHS/ NHIS/SHS/2018_SHS_Table_A-2.pdf

3. National Institutes of Health. National Heart, Lung, and Blood Institute. 2020 Focused Updates to the Asthma Management Guidelines: A Report from the National Asthma Education and Prevention Program Coordinating Committee Expert Panel Working Group. December 2020. Accessed February 17, 2021. www.nhlbi.nih.gov/health-topics/all-publicationsand-resources/2020-focused-updates-asthma-managementguidelines

4. Global Initiative for Asthma (GINA). Global Strategy for Asthma Management and Prevention, 2020. Accessed February 17, 2021. www.ginasthma.org/

5. Sobieraj DM, Weeda ER, Nguyen E, et al. Association of inhaled corticosteroids and long-acting $\beta$-agonists as controller and quick relief therapy with exacerbations and symptom control in persistent asthma: a systematic review and meta-analysis. JAMA. 2018;319:1485-1496.

6. Beasley R, Holliday M, Reddel HK, et al; Novel START Study Team. Controlled trial of budesonide-formoterol as needed for mild asthma. N Engl J Med. 2019;380:2020-2030.

7. Albuterol. GoodRx. Accessed February 17, 2021. www.goodrx. com/albuterol

8. Budesonide/formoterol. GoodRx. Accessed February 17, 2021 www.goodrx.com/budesonide-formoterol

\section{PRACTICE ALERT}

www.cdc.gov/vaccines/covid-19/info-by-product/moderna/ index.html\#: : :text=How\%20to\%20Store\%20the\%20Moderna\%20 COVID \%2D 19\%20Vaccine\&text=Vaccine\%20may\%20be\%20 stored\%20in,for\%20this\%20vaccine\%20is\%20tighter

6. Dooling K, Marin M, Wallace M, et al. The Advisory Committee on Immunization Practices' updated interim recommendation for allocation of COVID-19 Vaccine-United States, December 2020. MMWR Morb Mortal Wkly Rep. 2021;69:1657-1660.

7. FDA. Fact sheet for healthcare providers administering vaccine. [Pfizer-BioNTech]. Accessed February 17, 2021. www.fda.gov/ media/144413/download

8. FDA. Fact sheet for healthcare providers administering vaccine. [Moderna]. Accessed February 17, 2021. www.fda.gov/ media/144637/download

9. Mbaeyi SA, Bozio $\mathrm{CH}$, Duffy J, et al. Meningococcal vaccination recommendations of the Advisory Committee on Immunization Practices, United States, 2020. MMWR Recomm Rep. 2020;69:1-41.

10. Choi MJ, Cossaboom CM, Whitesell AN, et al. Use of Ebola vaccine: Recommendations of the Advisory Committee on Immunization Practices-United States, 2020. MMWR Recomm Rep. 2021;70:1-12.

11. CDC. Ebola background. Accessed February 17, 2021. www.cdc. gov/vaccines/acip/meetings/downloads/slides-2020-02/Ebola02-Choi-508.pdf 